\title{
RESENHA
}

\section{ALMICO, RITA DE CÁSSIA DA SILVA; GOODWIN, JAMES WILLIAM; SARAIVA, LUIZ FERNANDO (ORG.). NA SAÚDE E NA DOENÇA: HISTÓRIA, CRISES E EPIDEMIAS. REFLEXÕES DE HISTÓRIA ECONÔMICA NA ÉPOCA DA COVID-19. SÃO PAULO: HUCITEC,} 2020.

Por Douglas de Castro Carneiro*

Diante da crise pandêmica que se alastra no Brasil e no mundo, os estudos sobre a COVID-19, nas mais diferentes áreas das ciências, ganharam forças no meio acadêmico. Nesse cenário, foi produzida a obra Na saúde e na doença: História, Crises e Epidemias, Reflexões de História Econômica na época da Covid-19. O livro foi organizado por Rita de Cássia da Silva Almico, docente da Faculdade de Economia da Universidade Federal Fluminense (UFF), por James William Goodwin Jr., professor de História do Centro Federal de Educação Tecnológica de Minas Gerais (CEFET-MG) e por Luiz Fernando Saraiva, professor adjunto do Departamento de História da Universidade Federal Fluminense (UFF).

O prefácio faz menção a Eric Hobsbawn e às suas análises sobre a saúde e as doenças. O falecido historiador deu sua contribuição no sentido de pensar as complexas relações entre as doenças e as sociedades; destacar as formulações da ciência e das pessoas a respeito do corpo e sobre os conflitos que existiam (e existem) decorrentes de visões distintas; refletir sobre as causas das doenças e dos condicionantes sociais que as propagam e combatem. Todas essas questões permanecem atuais.

Na saúde e na doença é escrito por profissionais de diferentes áreas, tais como História, Geografia, Economia e Sociologia. A primeira parte do livro, intitulada "Pandemia vem do grego", se inicia com o texto do historiador Alexandre Santos Moraes, "Apolo e as marcas de sua epidemia na Ilíada”, texto no qual o autor procura sintetizar as marcas das epidemias na Iliada, de Homero. Moraes faz menções à peste ateniense, ocorrida em 429 a.C., que levou a óbito Péricles, como descrito por Tucídides, na guerra do Peloponeso, e enfatiza, inclusive, as disputas entre Aquiles e Agamêmnon naquele contexto. No capítulo "A peste em Atenas de Péricles", o historiador Alexandre Carneiro Cerqueira Lima analisa a peste em Atenas descrita por Péricles e o elogio aos mortos, realizado em um funeral coletivo representando o corpo social.

\footnotetext{
* Mestre em História pela Universidade Federal de Ouro Preto (UFOP). Doutorando em História pela Universidade Federal de Goiás (UFG). Bolsista CAPES-FAPEG. E-mail: douglascarneiiro229@gmail.com
} 
A segunda parte do livro tem por título "Conhecimento é poder (I): doenças, saberes médicos e ordem política". O capítulo incial, "Cirurgiões e seus saberes práticos em Minas setecentistas", escrito pela museóloga Ethiel Mizrahy Cuperschmid e por Maria do Carmo Salazar Martins, é parte de um estudo sobre a saúde dos escravos, no século XVIII, que eram submetidos a maus tratos e pouca alimentação e desprotegidos de doenças e pragas. As autoras abordam como, diante das adversidades das doenças, a medicina religiosa se espelhava na vida dos santos e dos mártires e em sua devoção para rogar ao todo poderoso a cura ou a solução de problemas. O historiador mineiro José Newton Coelho Meneses é autor do capítulo "'Águas passadas [...] movem moinhos', água, abastecimento, higiene e o processo saúde-doença na modernidade", que procura analisar os processos de saúde e doença na modernidade. Ainda nesta segunda parte, Glauber Miranda Florindo, em "Epidemia e Estado: um "jogo" antigo ainda jogado", analisa o Brasil do século XIX, em especial a atuação das câmaras municipais frente às epidemias.

$\mathrm{Na}$ terceira parte, intitulada "Gente vendida, doenças circulando: daquilo que não se quer ver", o historiador Roberto Borges Martins, em "Gripes, micróbios e lombrigas: nota sobre a primeira globalização da era moderna", afirma que, quando os espanhóis chegaram à América, as populações do México e do Peru tinham, há muitos séculos, densidade suficiente para sustentar as epidemias transmitidas de pessoas para pessoas. Já Luiz Fernando Saraiva, no capítulo "O fim do tráfico, o fim de um mundo e o início de outro", sintetiza o fim do tráfico e o início de um novo mundo". Nesse texto, o autor retoma uma das primeiras discussões historiográficas, sobre o porquê de o Brasil se manter coeso no processo de independência do final do século XVIII, ao contrário da América espanhola, que se fragmentou em dezenas de países. Elione Silva Guimarães, em "As pandemias e as populações invisíveis: do Brasil do século XIX ao Brasil da COVID-19”, procura fazer comparações entre as epidemias que afetaram as populações do Brasil no século XIX e no ano de 2029, enquanto Silvio Humberto Passos Cunha, em "Negro drama: um olhar sobre Salvador nesses tempos de pandemia Covid-19", analisa os espaços sociais de Salvador diante do tema do "Negro drama".

A quarta parte do livro tem por título "O perigo mora ao lado: doenças no espaço urbano". Para Pedro José de Oliveira Machado, autor do capítulo "Economia, saúde e comportamento social em dois momentos da história de Juiz de Fora”, o ano de 2020 ficará marcado por pandemias que afetarão as relações sociais e pessoais na cidade de Juiz de Fora. O autor remonta, ainda, aos séculos XIX e XX para abordar as relações entre economia e salubridade. Carlos Henrique Carvalho Ferreira Jr. e Fania Fridman, no texto "Epidemias e ordem pública: a cidade do Rio de Janeiro no século XIX", tratam de aspectos das epidemias que afetaram o Rio de Janeiro no século XIX. No capítulo "São Paulo na década de 1890 e em 2020: epidemias, enfrentamentos e reprodução de desigualdades", Fábio Alexandre dos Santos analisa as epidemias nos anos 1890 e em 2020, bem como as reproduções das desigualdades nesses contextos. A quarta parte se conclui com o texto de Maria Alice Rosa Ribeiro, "História que as epidemias nos contam", que analisa os questionamentos que não estavam presentes na documentação sobre as epidemias de febre amarela no final do século XIX. 
Na quinta parte do livro, "A peste, a fome, a guerra e a morte: os quatro cavaleiros da crise", Jorge Prata de Souza escreve "Epidemias e condições de saúde: a cólera durante a guerra do Paraguai", texto no qual analisa as epidemias durante a guerra do Paraguai. Marcos Lobato Martins, em "Tifo murino, cólera-morbo e o declínio da Companhia do Mucuri”, analisa as doenças nas terras da bacia do Mucuri durante o período colonial. Já James William Goodwin Jr., em “A peste e a fome: dois cavaleiros visitam Diamantina, MG", analisa a questão das epidemias na cidade de Diamantina em Minas Gerais. Teresa Cristina de Novaes Marques, em "Epidemia e cerveja: um paralelo entre 1918 e 2020", compara dois diferentes tipos de epidemias ao longo de cem anos. Rita de Cássia da Silva Almico, em "A morte sem pudor: reflexões sobre duas gripes", analisa as mortes diante da gripe espanhola e as mortes provocadas pela COVID-19.

Na sexta parte do livro, intitulada "A bolsa ou a vida: política econômica para pensar as crises", João Felippe Cury Marinho Mathias, no capítulo "Não há alternativa? Uma breve reflexão sobre o falso dilema ético e os efeitos da pandemia", analisa as questões que envolvem os efeitos morais e éticos da epidemia. Ivan Colangelo Salomão, em "Crise econômica, aprendizado político: a repetição trágica e farsesca da história”, analisa as crises econômicas presentes nos momentos em que as pandemias surgem. Victor Leonardo de Araujo, em "Crise econômica e ajuste fiscal: o que o Paeg nos ensina?", sintetiza seu pensamento sobre o que o Programa de Ação Econômica do Governo (PAEG) representa nas crises econômicas e sobre os ajustes fiscais promovidos pelo governo Brasilero. Fábio Pensavento conclui a sexta parte do livro com o capítulo "As crises financeiras do século XX e a COVID-19: comparar para medicar?", no qual analisa as crises econômicas que cercam a pandemia de COVID-19.

Na sétima parte do livro, "Conhecimento e Poder (II): solidariedade em tempos doentes”, Luiz Eduardo Simões de Souza escreve "A epidemia de meningite da ditadura militar", texto no qual analisa a crise de meningite durante o regime militar, demonstrando como o golpe de 1964 e a ditadura que a ele sobreveio representaram uma ruptura no direcionamento das políticas de saúde. O alinhamento político dos golpistas com o interesse externo e em benefício de setores detentores dos meios produtivos no país demandou que, uma vez no poder, se realinhasse a distribuição do produto em favor dos partícipes do butim. Aline Cristina Laier e Fernando Gaudereto Lamas, em "Acesso desigual ao conhecimento científico e seus recursos: uma breve análise sobre a epidemia do ebola na África", analisam as epidemias de ebola no continente africano. O vírus que ganhou o nome de ebola já havia sido identificado desde a década de 1970, mais especificamente em 1976, mas só ganhou notoriedade mundial na década de 1990, quando a imprensa internacional noticiou não somente a propagação do surto da doença em países africanos, como também a possibilidade de sua expansão para outros países, especialmente da Europa. No capítulo "Resistências nos tempos de pandemia no Brasil e na Argentina", Flávia Braga Vieira e Javier W. Ghibaldi indicam que há tempos os historiadores têm apontado a solidariedade e o comunalismo como valores que marcam e definem as lutas dos oprimidos. Os autores apontam para as propostas de organização de relações de trabalho mais igualitárias e de ajuda mútua, em oposição às mercantis capitalistas, reivindicadas hoje por cooperativas populares e redes de ajuda mútua, 
mas que já apareciam, de forma explícita, nos países centrais no sáculo XIX, justamente quando o projeto capitalista triunfava como sistema global. No Brasil, o momento mais expressivo da conjunção destas duas influências se deu no final da ditadura militar, mais especificamente no final dos anos 1970 e ao longo de toda a década de 1980, em um contexto de redemocratização pela base. Já na Argentina, as lutas nos bairros e nas fábricas fazem parte de uma forte identidade de classe operária e da própria formação urbana ao longo do século XX.

O livro Na saúde e na doença: História, Crises e Epidemias, Reflexões de História Econômica na época da Covid-19 representa uma tentativa de se pensar a história das epidemias dentro de um contexto global e de refletir sobre ações adotada por cada sociedade analisada e sua devida importância para o presente.

Data de submissão: 09/06/2020

Data de aprovação: 12/06/2020 